Review Article

\title{
Concurrent Guillain-Barré syndrome, transverse myelitis and encephalitis post-Zika: A case report and review of the pathogenic role of multiple arboviral immunity
}

\author{
Oscar Mancera-Páez ${ }^{\mathrm{a}, \mathrm{b}, 1}$, Gustavo C. Román ${ }^{\mathrm{c}, \mathrm{d}, *, 1}$, Rodrigo Pardo-Turriago ${ }^{\mathrm{a}}$, Yhojan Rodríguez , \\ Juan-Manuel Anaya ${ }^{\mathrm{e}}$ \\ ${ }^{a}$ Universidad Nacional de Colombia, Hospital Universitario Nacional, Faculty of Medicine, Department of Neurology, Bogotá, Colombia. \\ b David Cabello International Alzheimer Disease Scholarship Fund, Houston Methodist Hospital, Houston, TX, USA. \\ ${ }^{\mathrm{c}}$ Department of Neurology, Methodist Neurological Institute and the Institute for Academic Medicine Houston Methodist Research Institute, Houston Methodist Hospital, \\ Houston, TX, USA \\ d Weill Cornell Medical College, Department of Neurology, Cornell University, NY, New York, USA \\ ${ }^{\text {e }}$ Center for Autoimmune Diseases Research (CREA), School of Medicine and Health Sciences, Universidad del Rosario, Bogotá, Colombia
}

\section{A R T I C L E I N F O}

\section{Keywords:}

Zika virus

Guillain-Barré syndrome

Transverse myelitis

Acute disseminated encephalomyelitis

Post-infectious encephalitis

Colombia

\begin{abstract}
A B S T R A C T
We review post-infectious and post-vaccination neurological syndromes involving peripheral and central nervous system (CNS) and report an illustrative case of simultaneous occurrence of Guillain-Barré syndrome (GBS), confirmed by nerve conduction velocities, plus MRI-demonstrated transverse myelitis (TM) and acute encephalitis [acute disseminated encephalomyelitis] (ADEM + GBS) affecting a 24-year-old woman from Cúcuta, Colombia, who developed acute Zika virus (ZIKV) infection confirmed by serum reverse transcriptase-polymerase chain reaction (RT-PCR) and convalescent ZIKV IgG antibodies. With intensive care treatment, respiratory support, steroids, and intravenous immunoglobulin (IVIg), patient survived with residual flaccid paraparesis. She had preexisting immunity against Chikungunya virus (CHIKV) and Dengue virus (DENV) acquired before the arrival of ZIKV in Colombia. From reports in the Caribbean, Central and South America we review 19 cases of ZIKV-associated TM, encephalitis and ADEM occurring after a mean latent period of 10.5 days (range 1-96) post-infection. Although GBS and ADEM are usually considered post-infectious and associated with development of antibodies against peripheral nerve and CNS epitopes, we postulate that our case of ADEM + GBS is para-infectious, induced by acute ZIKV neurotropism boosted by active immunity against other arboviruses. Animal models of ZIKV demonstrated strong viral neurotropism enhanced by passive immunity with antibodies against arboviruses such as West Nile virus, CHIKV, or DENV. These considerations are relevant to prevent potential ZIKV vaccine-induced reactions involving central and peripheral nervous system.
\end{abstract}

\section{Introduction}

The flaviviruses (from the Latin, flavus, yellow) are small singlestranded RNA viruses associated with a wide range of neurological syndromes. The Flaviviridae family of viruses includes Yellow fever, Tick-borne encephalitis, Japanese encephalitis, West Nile (WNV), Dengue (DENV), and Zika (ZIKV) [1]. Recently, Acosta-Ampudia et al. [2] reviewed extensively the transmission, immunology and pathophysiology of the autoimmune neurological syndromes associated with ZIKV infection. From sylvatic reservoirs this arbovirus enters an urban cycle where transmission to humans occurs mainly by female Aedes mosquitoes-also carriers of DENV and Chikungunya (CHIKV), an alphavirus of the family Togaviridae. In addition, sexual transmission of ZIKV has been demonstrated with virus isolations from urine, semen, blood, maternal milk and tears. Zika infection is manifested by fever, maculopapular rash, conjunctivitis and rare uveitis, arthralgias, muscle pain and headache, but about $80 \%$ of infections are asymptomatic [2]. Nonetheless, ZIKV is neuroinvasive and capable of causing numerous neurological manifestations [2].

According to the World Health Organization (WHO) [3], a major

\footnotetext{
* Corresponding author: 6560 Fannin St., Suite 802, Houston, TX 77030, USA.

E-mail addresses: ogmancerap@unal.edu.co (O. Mancera-Páez), GCRoman@HoustonMethodist.org (G.C. Román), rpardot@unal.edu.co (R. Pardo-Turriago), johanintel@hotmail.com (Y. Rodríguez), juan.anaya@urosario.edu.co (J.-M. Anaya).

${ }^{1}$ These authors contributed equally to this work.
} 
concern of the Zika pandemic has been the viral neurotropism causing microcephaly [4] and Guillain-Barré syndrome (GBS) [1,2,5-7], along with other less frequent ZIKV-associated neurological complications including encephalitis, acute myelitis, encephalopathy, seizures, meningitis, and meningoencephalitis [1,2,7-9]. ZIKV infection of pregnant women causes microcephaly probably because the virus infects neural progenitor and glial cells, inducing apoptosis and excitotoxic cell death [10], apparently reaching the CNS via endothelial cells without damaging the blood-brain barrier [11]. Childhood stroke from ZIKV vasculitis [12] may result from infection of brain endothelial cells. The neurological complications of the Zika epidemic led the WHO to declare Zika a "public health emergency of international concern" [13]. On November 18, 2016, WHO declared the end of the global health emergency; however, the global risk assessment over the spread of ZIKV remains unchanged.

\subsection{The Zika virus epidemic}

ZIKV was first isolated in 1947 in a Rhesus monkey in the Ziika forest in Uganda, and the first serology-confirmed human cases of ZIKV infection were reported in Africa in 1952 [14]. The current outbreak of ZIKV originated in the island of Yap, Micronesia, in June 2007 [15,16]. This Flavivirus was considered clinically unimportant given that only 14 human symptomatic cases had been reported between 1947 and 2006 [17]. From Micronesia, the Zika epidemic spread to French Polynesia in 2013-2014 and then to other Pacific islands [2]. In May 2015, the first cases in the Americas were reported in northeastern Brazil followed by rapid spread of the virus throughout the Western Hemisphere [2]. In August 2016, the Pan American Health Organization (PAHO) reported 578,148 suspected cases of ZIKV in 45 countries and territories [18], from the southern USA to Brazil and northern Argentina (excluding continental Chile) potentially exposing 500 million people.

The neurological complications of ZIKV infection have been extensively reviewed $[1,2,8,9]$. In 2013, during the first large outbreak of Zika in French Polynesia, Cao-Lormeau et al. [19] documented the occurrence of GBS post-ZIKV infection. In 2015, local transmission of ZIKV was reported in Brazil [2]; in December 2015 it reached Colombia and by epidemiological week 28 of 2016 a total of 99,721 cases were registered [18]. In February 2016, almost 90 cases of GBS were reported [20,21] triplicating in 3 months the number of cases observed during the previous six years [22,23]. Other neurological complications, including transverse myelitis (TM) and acute disseminated encephalomyelitis (ADEM), were documented also [1,2].

\section{Methods}

We conducted a search of the medical literature for reports of neurological complications of Zika infection in the Americas and the Caribbean, according to the Preferred Reporting Items for Systematic Reviews and Meta-Analyses (PRISMA) statement [24] via PubMed until May 2018. We used the following key terms: "Guillain-Barré syndrome" [MeSH] OR Guillain Barre syndrome" [All Fields] OR "Myelitis, Transverse" [MeSH] OR "Myelitis" [All Fields] OR "Encephalomyelitis, Acute Disseminated" [MeSH] OR "Acute disseminated encephalomyelitis" [All Fields] OR "Encephalitis"” [All Fields]) AND ("Zika virus" [MeSH Term] OR "Zika virus infection" [MeSH Term] OR Zika [All Fields]). Further case reports and other studies were obtained by reference tracing of retrieved articles. We included any article in English, French, Portuguese, or Spanish reporting an association between ZIKV and neurological manifestations.

\subsection{Neurological Complications of ZIKV infection: Case report}

We report an illustrative case of a young woman from Cúcuta (Northeast Colombia) with ZIKV infection and evidence of arboviral immunity against CHIKV and DENV acquired prior to the arrival of Zika in Colombia. This patient developed acute Zika plus concurrent GBS, TM and ZIKV-associated encephalitis leading us to postulate potential mechanisms that could be associated with these extensive neurological complications of ZIKV infection. The geographical characteristics, neuroepidemiology, immunology, and neurological manifestations of the Zika outbreak in Cúcuta, Colombia, were previously described by two of us (JMA, YR) [2,7]. This case was previously listed as radiculomyelopathy [7] but brain MRI documented the presence of ZIKV-associated encephalitis.

In January 2014, a 24-year old Colombian woman was diagnosed with CHIKV infection manifested by polyarthralgias, malaise, nausea and a pruritic macular rash in the trunk and the legs. IgM antibody titer against CHIKV was positive (1:474, January 2014, ELISA, Euroimmun Luebeck, Germany) as well as the IgG antibody titer ( $>1.1$, Euroimmun Index performed at the Center for Autoimmune Diseases Research, CREA). The patient also had serological evidence of previous infection with DENV (IgM titer 1:32, Euroimmun, Luebeck, Germany).

The patient recovered completely from the CHIKV infection, but on 17 January 2016 , she developed vomiting, fever $\left(40^{\circ}-42^{\circ} \mathrm{C}\right)$, myalgias and severe epigastric pain spreading in a band-like pattern around her back. She was admitted to the hospital, and ZIKV infection was identified at the Colombian National Institute of Health by reverse-transcriptase-polymerase chain reaction (RT-PCR Taq-Path Zika Virus, Thermo Fisher, cycle threshold (Ct) positivity $\leq 38.00$ ). In May 2016, CREA laboratories confirmed the presence of autoantibodies against ZIKV: IgG antibodies were positive with a titer of 2.9 (ZIKV Euroimmun, Luebeck, Germany) but, as expected, IgM antibodies were negative at 0.1 (ZIKV Euroimmun, Luebeck, Germany); the plate neutralization test was positive (PRNT90 > 1/128).

About $24 \mathrm{~h}$ after admission she developed urinary retention and bilateral lower limb weakness with foot drop. The weakness ascended and two days after admission she developed flaccid quadriplegia, became confused, hypoxemic, and required respiratory support. Autoimmunity profile was negative including: rheumatoid factor, antiaquaporin 4 antibodies, systemic lupus erythematosus, sarcoidosis, anti-phospholipid syndrome, anti-CCP antibodies, thyroid peroxidase (TPO) antibodies, thyroid thyroglobulin antibodies, B2GPI IgG, B2GPI IgG, ACA III IgM, ACA III IgG, ANAs, ANCAs, and Sjögren's syndrome panel. The patient received a 5-day course of intravenous immunoglobulin (IVIg) and methyl-prednisolone resulting in improvement of the level of consciousness.

In the absence of cerebrospinal fluid (CSF) examination the diagnosis of GBS was confirmed (Level 2: Brighton Collaboration GBS Working Group criteria [25]) based on clinical neurophysiology examination that included nerve conduction velocities (NCV) [Table 1A] and needle electromyography (EMG) [Table 1B]. On 23 February 2016, absence of the $\mathrm{H}$ reflex was documented and NCV showed slow nerve conduction velocities in median and ulnar nerves with abnormal temporal dispersion; compound muscle action potentials (CMAPs) were prolonged and had reduced amplitude. EMG showed signs of denervation in first dorsal interosseous muscles. NCV of tibial and peroneal nerves showed no response at anterior tibialis and peroneus longus muscles. Upper extremity sensory nerve action potentials (SNAPs) were present. Conduction block was observed in lower limbs, with absent SNAPs at sural and superficial peroneal nerves. EMG disclosed increased insertion activity with denervation signs, positive sharp waves, fibrillations and severely reduced recruitment in lower limbs; motor units in lower limb muscles were neuropathic and polyphasic. The above pattern is consistent with acute motor axonal neuropathy (AMAN), as previously reported in ZIKV-associated GBS in French Polynesia [19], Brazil [8], and Colombia [5-7].

About one month after onset, MRIs of the brain and spinal cord were performed. Brain MRI on T2 and fluid-attenuated inversion recovery (FLAIR) sequences disclosed multifocal non-enhancing hyperintense lesions located in the periventricular white matter and subcortical areas [Fig. 1A,B]. MRI of the cervical, thoracic, and lumbar spine, with and 
A

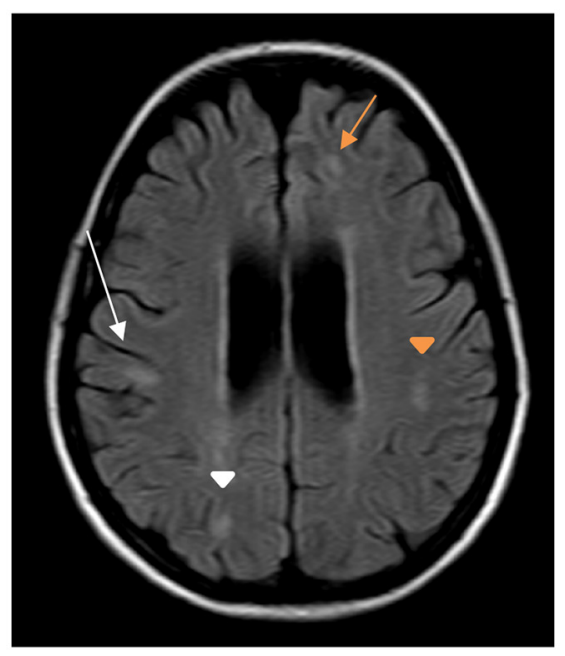

\section{B}

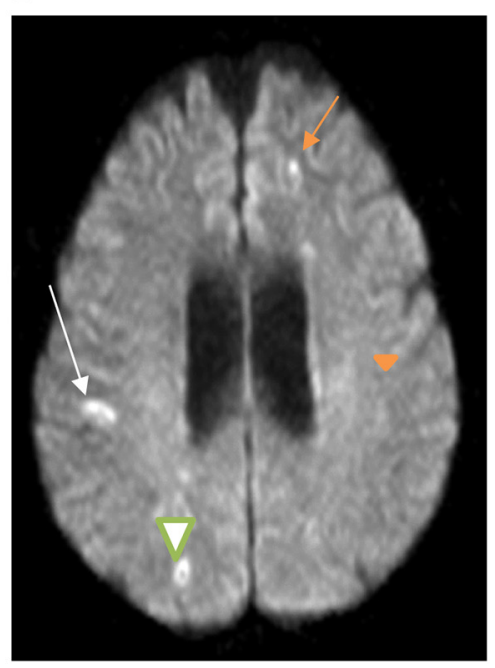

$\mathrm{B}$

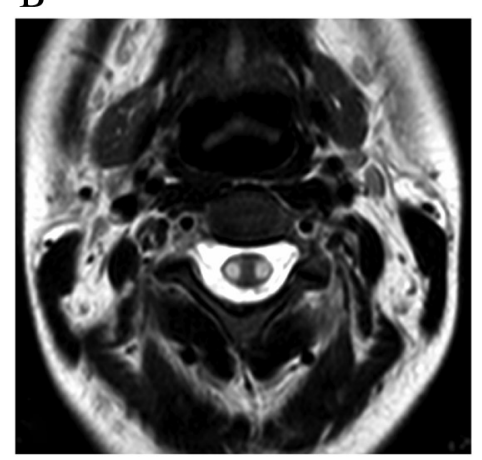

Fig. 1. Magnetic resonance imaging (MRI) showing encephalitis lesions in a patient with acute Zika and ZIKVmyelitis + GBS. (A) Fluid-attenuated inversion recovery (FLAIR) sequence showing non-enhancing hyperintense white matter lesions located in the left frontal (arrow) and left parietal (arrowhead) periventricular regions and right temporal (white arrow) and occipital (white arrowhead) subcortical areas. (B) Diffusion-weighted imaging (DWI) sequence showing increased diffusion in left frontal, right parietal and occipital lesions.
A

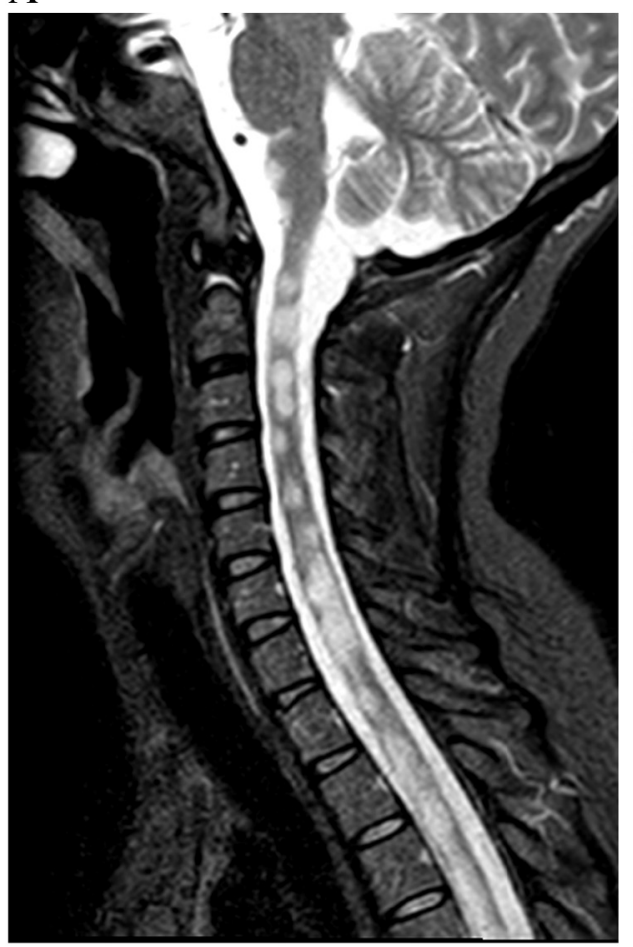

Fig. 2. Magnetic resonance imaging (MRI) showing myelitis in patient with acute Zika virus infection and ZIKV-GBS. (A) T2 sequences showing several zones with hypersignal in ventral pons, pontomedullary junction, cervical cord C1-C7, thoracic cord T1-T12, and conus medullaris (not illustrated). (B) Axial T2 sequence showing hypersignal involving lateral columns in the cervical cord C1-C2. without gadolinium contrast, demonstrated multiple T2 hyperintense, non-enhancing lesions in the medulla oblongata, cervical and thoracic spinal cord [Fig. 2A, B]. In summary, the clinical presentation, neurophysiology tests, and MRI lesions confirmed the presence of ZIKV-associated ADEM + GBS.

The patient remained in ICU for six weeks requiring respiratory support, nasogastric tube feeding and treatment for numerous complications including antibiotic-resistant Acinetobacter baumannii septicemia and basal pneumonia. Eventually, she was weaned from the respirator; her level of alertness improved, and she was able to communicate. On neurological examination, she had residual unilateral optic neuritis, generalized areflexia, sensory loss at the C5-T2 levels, with absent perception of touch, temperature and proprioception from T6 down into the lower limbs. The bilateral plantar response was neutral; Hoffman sign was positive in both hands. She left the hospital and underwent physical therapy and rehabilitation. One year later, the patient is cognitively normal, with a Montreal Cognitive Assessment (MoCA) [26] score of 30/30. The flaccid paraplegia with global areflexia and atrophy of leg muscles persists; she is wheelchair-bound but is beginning to walk with support. Incontinence of urinary bladder and bowels remain unchanged, and there is complete loss of sensation in the lower limbs.

\section{Discussion}

This case highlights several important aspects of the neurological manifestations of ZIKV including the concurrent development of GBS and encephalomyelitis during the acute phase of the ZIKV infection demonstrated by RT-PCR. It has been reported in the literature that the neurological complications of ZIKV infection can be either para-infectious, i.e., due to direct viral neurotropism, or post-infectious, i.e., resulting from immune-mediated reactions against the virus. We review 
the original descriptions of para-infectious, post-infectious and postvaccination neurological syndromes and summarize the reported cases of TM and ADEM in the American continent. We conclude by discussing the implications of the presence in our patient of serological evidence of immunity against CHIKV and DENV suggesting that preexistent arboviral immunity could be relevant to the coexistence of widespread neurological involvement of both PNS and CNS in this patient.

\subsection{Para-infectious, post-infectious and post-vaccination neurological syndromes}

In 1956, Miller, Stanton and Gibbons [27] reviewed the para-infectious encephalomyelitis and related syndromes occurring simultaneously or shortly after the onset of an acute viral infection such as mumps, which is capable of causing ADEM [28] and other immune responses affecting the brain, spinal cord as well as the peripheral nervous system (PNS). It is generally accepted that viral neurotropism is the main mechanism of injury. Recent examples include the polio-like complications of WNV [29] and of enterovirus D68 strain [30,31].

In 1969, Charles Poser [32] in a now-classic paper proposed the term "acute disseminated vasculomyelinopathy" to designate some post-infectious and post-vaccination neurological complications affecting both the central nervous system (CNS) and the PNS after a period of latency ranging from a few days to several weeks [33]. He emphasized that these immune reactions in the CNS are characterized neuropathologically by perivenous vascular inflammation frequently affecting the myelin. Post-infectious reactions following varicella and rubella may involve the brain itself, spinal cord, spinal roots, and peripheral nerves, manifested by various clinical syndromes such as ADEM, optic neuritis, papilledema, isolated ophthalmoplegia, brachial neuritis and other mononeuropathies.

\subsubsection{Guillain-Barré syndrome (GBS)}

GBS has been considered a post-infectious complication associated with production of antibodies against peripheral nerve gangliosides and other components of axons, myelin or nerve roots [34], occurring after gastrointestinal and upper respiratory tract infections caused by bacterial agents such as Campylobacter jejuni, Mycoplasma pneumoniae, and at least 10 other bacterial microorganisms [34]. GBS occurred also with increased incidence following swine flu vaccination [35]. Viral infections associated with GBS [34] include cytomegalovirus (CMV), herpes simplex virus, varicella-zoster virus, Epstein-Barr virus (EBV), hepatitis $B$ virus, human immunodeficiency virus, and parainfluenza type-3 virus [36]. Acosta-Ampudia et al. [2], have emphasized that arboviral infections -including ZIKV- alter the immune recognition of peripheral nerve, possibly causing the myelin and underlying axon not to be recognized as self-tissue, leading to abnormal autoimmune responses and GBS. Among the flaviviruses, Dengue infections [37,38], particularly the neurotropic serotypes DENV-2 and DENV-3 [39], have been associated with GBS and other neurological complications [40], including meningoencephalitis, ADEM [41], cerebellar syndrome, neuromyelitis optica, as well as a longitudinally extensive form of TM [42].

Prior to the current ZIKV pandemic it was believed that the latency period following infection was required for the production of antibodies cross-reacting by molecular mimicry with epitopes in peripheral nerves leading to myelin or axonal injury. Thus, Anaya et al. [7] in Cúcuta (Colombia) found a lag time of 7 days (interquartile range 2-14.5) between ZIKV infection and neurological symptoms. The incidence of GBS increased 4.41-fold secondary to ZIKV infection. Serum antiganglioside antibodies were found in $71.43 \%$ of patients with acute inflammatory demyelinating polyneuropathy (AIDP) and in $14.28 \%$ of patients with axonal forms (AMAN). Anaya and colleagues [7] performed a case-control study comparing 29 patients with ZIKV-GBS and 74 matched-controls with ZIKV infection alone and found that all GBS patients were positive for IgG antibodies against both ZIKV and DENV, and $69 \%$ were positive also for CHIKV [7]. Previous infection with $M$. pneumoniae increased 4-fold the risk of GBS (OR: 3.95; 95\% CI $=1.44-13.01 ; p=.006$ ). No differences in antibody levels against $C$. jejuni, EBV and CMV were observed [7].

Based on their experience in French Polynesia, Gérardin et al. [43] postulated that Zika-related GBS might have a different mechanism than the usual post-viral GBS. They suggested that a hyperacute immune response potentially occurs in patients who are Dengue seropositive since there is cross-reactivity of DENV with ZIKV [44]. In Colombia, Parra et al. [6] concluded that $48 \%$ of the cases of ZIKV-GBS had para-infectious onset. As reported by Anaya et al. [7], the presence of serological evidence of immunity against CHIKV and DENV in 100\% of their ZIKV-GBS cases diagnosed in Colombia, as illustrated here, would support the proposal of Gérardin et al. [43] from French Polynesia, resulting in hyperacute immune response shortening the time between ZIVK infection and onset of neurological manifestations.

Nonetheless, Timmings and colleagues [45] from New Zealand favor a direct neurotropic effect of ZIKV on peripheral nerves as a possible para-infectious mechanism of action. Their patient was a man infected in Tonga (South Pacific Polynesia) who developed GBS concurrently with demonstrated Zika viremia but with negative ZIVK isolation in the CSF and serological absence of previous viral antibodies against Dengue and other flaviviruses; MRIs of brain and spinal cord were normal [46]. The two mechanisms may be at play in different environments and further studies will be required to define the actual pathogenesis of ZIKV-associated GBS.

\subsubsection{Acute transverse myelitis (ATM) and acute disseminated encephalomyelitis (ADEM)}

ZIKV-ATM and ZIKV-ADEM have rarely been reported in the American continent and the Caribbean [47-56]. We were able to find a total of 19 patients with myelitis associated with ZIKV infection [Table 2]. Clinically, these cases can be separated in the following variants: Acute transverse myelitis (12 cases), Encephalomyelitis (6 cases), plus the single case of $A D E M$ plus GBS reported here.

Acute transverse myelitis (ATM): Most patients presenting with ZIKVATM were men $(8 / 12,66.6 \%)$ with a mean age of 23 years (range 15-43) (except for an 86-year-old man [50]). The latency period between Zika symptoms and neurological manifestations ranged from 7 days to 96 days (mean 18 days). The affected geographic areas included the Caribbean (Guadeloupe, French Antilles; San Juan, Puerto Rico), Colombia (Cúcuta), and Brazil (Rio de Janeiro and Pará). The clinical presentation is similar: Mécharles et al. [47] described a 15year-old girl infected with ZIKV in the French Caribbean island of Guadeloupe who presented with back pain, left hemiparesis, paraparesis and signs of acute cervicothoracic myelitis, confirmed by MRI. She developed urinary retention similar to the symptom of onset in our patient, and physical examination disclosed an enlarged urinary bladder. Brain MRI was normal, and she recovered with steroids. Palacios et al. [48] reported a 23-year-old man from Colombia who 15 days following an acute ZIKV infection developed pelvic pain, flaccid paraplegia with brisk leg reflexes, urinary retention and evidence on MRI of longitudinally extensive myelitis from $\mathrm{C} 1$ down to the conus medullaris. The patient recovered after steroid treatment complemented with plasmapheresis. Anaya et al. [7] reported a cluster of 6 patients with ZIKV-myelitis living in the same region of northeastern Colombia as the patient reported here. After a median latent period of 32 days (range 13-96 days) following acute ZIKV infection, they all developed a similar neurologic syndrome of transverse myelitis with severe longitudinal myelitis affecting cervical and thoracic spinal cord. In addition to positive IgG antibodies against ZIKV, all patients also had serological evidence of immunity against CHIKV and DENV [7]. It is unclear if the cluster of neurological cases in Colombia resulted from a particular neurotropism of the ZIKV strain, or from the additive effect on the host with acute ZIKV infection of multiple antibodies against other arboviruses, in particular, DENV and CHIKV. For instance, ATM has been reported in subjects who are hyper-responders to hepatitis B 
vaccination with very high antibody titers in the CSF [57]. The exact mechanism of production of ZIKA-ATM remains unknown.

Encephalomyelitis: We found 5 reported cases of ZIKV-associated encephalomyelitis and a single patient with ADEM [53] (Table 2). Age at onset in 3 cases ( 2 women and 1 man) ranged from 18 to 26 years (mean 21 years); the oldest patient was a 69-year-old woman [55]. Three cases each occurred in the Dominican Republic and Brazil (Rio de Janeiro and Pernambuco). The latency period between Zika symptoms and neurological symptoms ranged from 1 to 21 days (mean 10 days). The clinical presentation is exemplified by the case reported by Roth et al. [54] of ZIKV encephalomyelitis in an 18-year-old woman from the Dominican Republic in the Caribbean who six weeks after an acute ZIKV infection presented with numbness of the legs from the T6 dermatome down, hyperreflexia and Babinski sign. MRI showed myelitis in the cervical and thoracic cord; the brain MRI demonstrated multifocal subcortical and callosal white matter lesions similar to those of our patient. The patient recovered with corticosteroid treatment. Given the delay between the acute ZIKV infection and the onset of neurological symptoms (14 days), a diagnosis of post-infectious ZIKV-EM was proposed [54].

\subsection{The Role of Other Arboviral Infections}

ZIKV is the latest arboviral infection to affect the American continent. According to Fauci and Morens [58] four arboviral epidemic diseases have occurred in the last 20 years in the American continent: DENV in the 1990s, WNV in 1999, CHIKV in 2013, and ZIKV since 2015. The Dengue outbreak that preceded and co-circulated with Zika infection probably resulted in anti-flavivirus cross-immunity that may have induced antibody-dependent enhancement leading to ZIKV-GBS [59-61]. The potential role of Chikungunya infection [51], a Togaviridae family arbovirus, that affected this patient four months prior to the ZIKV infection, remains unexplored. An epidemiological increase of Dengue and Chikungunya cases occurred in Colombia from July 2014 until July 2015 and preceded the outbreak of Zika infection by three months. There are reports of CHIKV-GBS, meningoencephalitis, and myelitis during CHIKV outbreaks around the world [51]. Although other members of the Flaviviridae family such as Yellow fever, Saint Louis encephalitis, Japanese encephalitis, WNV, DENV, and CHIKV are capable of producing neurological disease, the broad spectrum of neurological manifestations of Zika virus is unprecedented.

\subsubsection{ZIKV-GBS, transverse myelitis and encephalomyelitis: Para- infectious or Post-infectious}

The possible pathogenesis of ZIKV-associated neurological disorders has been recently reviewed [1,2,8,10,61]. Miner and Diamond [59] postulated that congenital ZIKV infection might be related to the high prevalence of pre-existing cross-reactive immune responses associated with DENV [44]. Similar observations in GBS patients from French Polynesia [43] and Colombia [6,7] suggest that a hyperacute immune response may occur resulting in para-infectious onset. Serological evidence of previous immunity against both CHIKV and DENV was found in Colombia [7,8]. Nevertheless, as reported by Anaya et al. [8], no significant differences for arboviruses (i.e., DENV and CHIKV) between GBS cases and controls were observed but GBS cases more frequently had evidence of prior M. pneumoniae infection. These observations reinforce the view that the neurotropism of ZIKV may cause the simultaneous compromise of CNS and PSN [45,46]. In Brazil, da Silva and colleagues [49] found that $50 \%$ of ZIKV-encephalitis cases also have neuromuscular findings and almost half of the patients with ZIKVassociated GBS present enhancement of cranial nerves on MRI scans manifested by dysphagia and facial numbness. Moreover, a variety of ZIKV-GBS subtypes occurred including AIDP, AMAN, acute motor and sensory axonal neuropathy, and Miller Fisher syndrome variant $[1,7,8,49]$. A purely sensory polyneuropathy has also been reported [62].
Among the flaviviruses, West Nile virus causes a poliomyelitis syndrome with acute flaccid paralysis, along with myositis, myocarditis, brachial plexopathy, AMAN, and GBS [63]. Patients with GBS produce antibodies against human peripheral nerve gangliosides $[1,2,7-9,61]$; in AIDP the target of the immune-related injury is the myelin sheath and Schwann-cells, while in AMAN the axons of the nerve or axolemma membranes are injured [1,2,7-9]. In vitro studies have shown ZIKV-induced axonal and myelin changes in CNS cultures from cytokines induced by the virus [64,65]. Lucchese and Kanduc [66] demonstrated analogy of $>500$ epitopes with high peptide overlap between the ZIKV polyprotein and human proteins related to myelin, demyelination, and axonal neuropathy. This finding supports cross-reactivity as a potential pathogenic mechanism in ZIKV-GBS.

Some experimental animal studies have demonstrated ZIKV neurotropism [67-69]. Of relevance for the present case is the experimental model of myelitis developed by Fernandes et al. [70] using Swiss mice inoculated with a strain of ZIKV isolated from the recent outbreak in Brazil. At 12 days post-inoculation the mice developed bladder distention due to urinary retention and spinal cord involvement. Brain tissue showed perivascular leukocyte cuffing, neuronal death, intense astrogliosis, and increased expression of glial fibrillary acidic protein (GFAP). The spinal cord showed myelitis with few hypertrophic astrocytes and long cellular processes. In addition, hemorrhagic changes occurred in the cortex, hippocampus, and spinal cord. Immunohistochemical markers in brain and cerebellum demonstrated intense crossed immunity against DENV, but only rarely positive immunity was noted in the spinal cord. A complete neuropathological study of congenital cases of ZIKV infection by Chimelli and coworkers [71] showed spinal lesions consisting of motor cell loss sparing dorsal root ganglia, dorsal nerve roots, and spinal columns. There was mild lympho-histiocytic inflammation. In situ hybridization showed meningeal, germinal matrix, and neocortical ZIKV infection. A secondary ischemic process was also present. Bardina et al. [72] in a murine model of ZIVK infection described increased morbidity and mortality following the injection of convalescent plasma from DENV- or WNV-infected mice; plasma injections caused marked viremia, high fever, and increased ZIKV viral load in spinal cord and testes. These authors [72] proposed an antibody-dependent enhancement (ADE) mechanism mediated in vitro through IgG engagement of $\mathrm{Fc}$-Gamma receptors to potentiate the ZIKV infection.

In summary, the current Zika epidemic has resulted in unexpected increase in the incidence of microcephaly and other congenital neurological defects as well as ZIKV-GBS in adults. We report a case of simultaneous ZIKV-associated ADEM + GBS indicative of the potential of ZIKV to affect CNS and PNS concurrently. ZIKV infection may induce both a typical post-infectious GBS, as well as a concurrent para-infectious direct infection of the nervous system enhanced by existing arboviral and herpesvirus immunity. Regardless of the definitive pathophysiology of the ZIKV neurological complications, it appears important to take into account the phenomenon of ADE or antibodymediated potentiation for the design of ZIKA vaccines [73,74] in order to prevent potential vaccine-induced reactions involving the nervous system.

\section{Acknowledgments}

The authors would like to thank Dr. Pablo Lorenzana-Pombo and Dr. Fernando Ortiz for the review and analysis of the clinical neurophysiology and EMG studies in this patient. Dr. Mancera-Páez was supported by the David Cabello International Alzheimer Disease Scholarship Fund, Houston Methodist Hospital, Houston, Texas. Dr. Román's research is supported by The Jack S. Blanton Presidential Distinguished Chair, the Fondren Fund, and the Wareing Family Fund at Houston Methodist Hospital, Houston, Texas, USA. 


\section{References}

[1] L.S. Muñoz, B. Parra, C.A. Pardo, on behalf of the Neuroviruses Emerging in the Americas Study, Neurological implications of Zika virus infection in adults, J. Infect. Dis. 216 (2017), https://doi.org/10.1093/infdis/jix511 (S897-S905).

[2] Y. Acosta-Ampudia, D.M. Monsalve, L.F. Castillo-Medina, Y. Rodríguez, Y. Pacheco, S. Halstead, H.J. Willison, J.M. Anaya, C. Ramírez-Santana, Autoimmune neurological conditions associated with Zika virus infection, Front. Mol. Neurosci. 11 (2018) 116, , https://doi.org/10.3389/fnmol.2018.00116.

[3] World Health Organization (WHO). WHO Director-General summarizes the outcome of the Emergency Committee regarding clusters of microcephaly and GuillainBarré syndrome. WHO 2016.http://www.who.int/ mediacentre/news/statements/ 2016/ emergency-committee-zika-microcephaly/en/ (accessed June 11, 2017).

[4] M.A. Johansson, L. Mier-Y-Teran-Romero, J. Reefhuis, S.M. Gilboa, S.L. Hills, Zika and the risk of microcephaly, N. Engl. J. Med. 375 (2016) 1-4.

[5] O. Pacheco, M. Beltran, C.A. Nelson, D. Valencia, N. Tolosa, S.L. Farr, A.V. Padilla, V.T. Tong, E.L. Cuevas, A. Espinosa-Bode, L. Pardo, A. Rico, J. Reefhuis, M. González, M. Mercado, P. Chaparro, M. Martínez Durán, C.Y. Rao, M.M. Muñoz, A.M. Powers, C. Cuellar, R. Helfand, C. Huguett, D.J. Jamieson, M.A. Honein, M.L. Ospina Martínez, Zika virus disease in Colombia - Preliminary report, N. Engl. J. Med. (2016 Jun 15), https://doi.org/10.1056/NEJMoa1604037.

[6] B. Parra, J. Lizarazo, J.A. Jiménez-Arango, A.F. Zea-Vera, G. González-Manrique, J. Vargas, J.A. Angarita, G. Zuñiga, R. Lopez-González, C.L. Beltrán, K.H. Rizcala, M.T. Morales, O. Pacheco, M.L. Ospina, A. Kumar, D.R. Cornblath, L.S. Muñoz, L. Osorio, P. Barreras, C.A. Pardo, Guillain-Barré syndrome associated with Zika virus infection in Colombia, N. Engl. J. Med. 375 (2016) 1513-1523.

[7] J.M. Anaya, Y. Rodríguez, D.M. Monsalve, D. Vega, E. Ojeda, D. González-Bravo, M. Rodríguez-Jiménez, C.A. Pinto-Díaz, P. Chaparro, M.L. Gunturiz, A.A. Ansari, M.E. Gershwin, N. Molano-González, C. Ramírez-Santana, Y. Acosta-Ampudia, A comprehensive analysis and immunobiology of autoimmune neurological syndromes during the Zika virus outbreak in Cúcuta, Colombia, J. Autoimmun. 77 (2017) 123-138, https://doi.org/10.1016/j.jaut.2016.12.007.

[8] A.Q.C. Araujo, M.T.T. Silva, A.P.Q.C. Araujo, Zika virus-associated neurological disorders: A review, Brain 139 (2016) 2122-2130.

[9] K.L. Tyler, K.L. Roos, The expanding spectrum of Zika virus infections of the nervous system, JAMA Neurol. 74 (2017) 1169-1171, https://doi.org/10.1001/ jamaneurol.2017.1471.

[10] R.S.S. Azevedo, J.R. de Sousa, M.T.F. Araujo, A.J. Martins Filho, B.N. de Alcantara, F.M.C. Araujo, M.G.L. Queiroz, A.C.R. Cruz, B.H. Baldez Vasconcelos, J.O. Chiang, L.C. Martins, L.M.N. Casseb, E.V. da Silva, V.L. Carvalho, B.C. Baldez Vasconcelos, S.G. Rodrigues, C.S. Oliveira, J.A.S. Quaresma, P.F.C. Vasconcelos, In situ immune response and mechanisms of cell damage in central nervous system of fatal cases microcephaly by Zika virus, Nature Sci. Reports 8 (1) (2018), https://doi.org/10. 1038/s41598-017-17765-5.

[11] M.P. Papa, L.M. Meuren, S.V.A. Coelho, C.G. de O. Lucas, Y.M. Mustafá, F. Lemos Matassoli, P.P. Silveira, P.S. Frost, P. Pezzuto, M.R. Ribeiro, A. Tanuri, M.L. Nogueira, L. Campanati, M.T. Bozza, H.A. Paula Neto, P.M. Pimentel-Coelho, C.P. Figueiredo, R.S. Aguiar, L.B. Arruda, Zika virus infects, activates, and crosses brain microvascular endothelial cells, without barrier disruption, Front. Microbiol. 8 (2017) 2557, , https://doi.org/10.3389/fmicb.2017.02557.

[12] A. Landais, A. Césaire, M. Fernandez, S. Breurec, C. Herrmann, F. Delion, P. Desprez, Zika vasculitis: A new cause of stroke in children? J. Neurol. Sci. 383 (2017) 211-213, https://doi.org/10.1016/j.jns.2017.10.045.

[13] A. Gulland, Zika virus is a global public health emergency, declares WHO, Br. Med. J. 352 (2016) i657.

[14] G.W. Dick, S.F. Kitchen, A.J. Haddow, Zika virus. I. Isolations and serological specificity, Trans. R. Soc. Trop. Med. Hyg. 46 (1952) 509-520.

[15] R.S. Lanciotti, O.L. Kosoy, J.J. Laven, J.O. Velez, A.J. Lambert, A.J. Johnson, S.M. Stanfield, M.R. Duffy, Genetic and serologic properties of Zika virus associated with an epidemic, Yap State, Micronesia, 2007, Emerg. Infect. Dis. 14 (2008) 1232-1239, https://doi.org/10.3201/eid1408.080287.

[16] M.R. Duffy, T.-H. Chen, W.T. Hancock, A.M. Powers, J.L. Kool, R.S. Lanciotti, M. Pretrick, M. Marfel, S. Holzbauer, C. Dubray, L. Guillaumot, A. Griggs, M. Bel, A.J. Lambert, J. Laven, O. Kosoy, A. Panella, B.J. Biggerstaff, M. Fischer, E.B. Hayes, Zika virus outbreak on Yap Island, Federated States of Micronesia, N. Engl. J. Med. 360 (2009) 2536-2543.

[17] D.G. McNeil Jr., Zika: The Emerging Epidemic, W.W. Norton \& Company, New York, 2016

[18] PAHO WHO, Zika Cumulative Cases - 25 August 2016. Pan American Health Organization. World Health Organization. (Available on line at): http://www.paho. org/hq/index.php?option $=$ com_content\&view $=$ article\&id $=12390 \% 3$ Azika-cumulative-cases\&catid $=8424 \% 3$ Acontents\&Itemid $=42090 \&$ lang $=$ en $($ accessed June 1, 2018).

[19] V.M. Cao Lormeau, A. Blake, S. Mons, S. Lastere, C. Roche, J. Vanhomwegen, T. Dub, L. Baudouin, A. Teissier, P. Larre, A.L. Vial, C. Decam, V. Choumet, S.K. Halstead, H.J. Willison, L. Musset, J.C. Manuguerra, P. Despres, E. Fournier, H.P. Mallet, D. Musso, A. Fontanet, J. Neil, F. Ghawché, Guillain-Barré syndrome outbreak associated with Zika virus infection in French Polynesia: A case-control study, Lancet 387 (2016) 1531-1539, https://doi.org/10.1016/S0140-6736(16) 00562-6.

[20] Organización Panamericana de la Salud. Epidemiologic Report WHO-OPS, Resumen de la situación de la epidemia por virus Zika en las Américas. Zika Actual. Epidemiológica OPS. 2017. http://www.paho.org/hq/index.php?option = com docman\&task $=$ doc_view\&Itemid $=270 \&$ gid $=40224 \&$ lang $=$ es $($ accessed June 1 , 2017).
[21] WHO 2017. WHO | Guillain-Barré syndrome - Colombia and Venezuela. WHO 2016. http://www.who.int/csr/don/12-february-2016-gbs-colombia-venezuela/ en/ (accessed June 12, 2017)

[22] R. Pardo-Turriago, Neuropatías tropicales, un lastre del subdesarrollo y un reto en un mundo globalizado, Biomedica 37 (2017) S5-S8.

[23] R. Pardo-Turriago, Zika. A pandemic in progress and an epidemiological challenge, Colombian J. Anesthesiol. 44 (2016) 86-88

[24] D. Moher, A. Liberati, J. Tetzlaff, D.G. Altman, P. Group, Preferred reporting items for systematic reviews and meta-analyses: The PRISMA statement. PLoS Med. 6 (209) e1000097. doi:https://doi.org/10.1371/journal.pmed.1000097.

[25] J.J. Sejvara, K.S. Kohl, J. Gidudu, A. Amato, N. Bakshic, R. Baxter, D.R. Burwend, D.R. Cornblath, J. Cleerboutf, K.M. Edwardsg, U. Heiningerh, R. Hughesi, N. KhuriBulosj, R. Korinthenbergk, B.J. Lawl, U. Munrom, H.C. Maltezoun, P. Nello, J. Oleskep, R. Sparksq, P. Velentgasr, P. Vermeers, M. Wiznitzertfor The Brighton Collaboration GBS Working Group, Guillain-Barré syndrome and Fisher syndrome: Case definitions and guidelines for collection, analysis, and presentation of immunization safety data, Vaccine 29 (2011) 599-612.

[26] Z.S. Nasreddine, N.A. Phillips, V. Bédirian, S. Charbonneau, V. Whitehead, I. Collin, J.L. Cummings, H. Chertkow, The Montreal Cognitive Assessment, MoCA: A brief screening tool for mild cognitive impairment, J. Am. Geriatr. Soc. 53 (2005) 695-699.

[27] H.G. Miller, J.B. Stanton, J.L. Gibbons, Para-infectious encephalomyelitis and re lated syndromes: A critical review of the neurological complications of certain specific fevers, Q. J. Med. 25-100 (1956) 427-505.

[28] H.G. Miller, J.B. Stanton, J.L. Gibbons, Acute disseminated encephalomyelitis and related syndromes, Br. Med. J. 1 (520) (1957) 668-672.

[29] P.A. Swanson II, D.B. McGavern, Viral diseases of the central nervous system. Curr. Opin. Virol. 11 (2015) 44-54. doi: https://doi.org/10.1016/j.coviro.2014.12.009.

[30] A.L. Greninger, S.N. Naccache, K. Messacar, A. Clayton, G. Yu, S. Somasekar, S. Federman, D. Stryke, C. Anderson, S. Yagi, S. Messenger, D. Wadford, D. Xia, J.P. Watt, K. Van Haren, S.R. Dominguez, C. Glaser, G. Aldrovandi, C.Y. Chiu, A novel outbreak enterovirus D68 strain associated with acute flaccid myelitis cases in the USA (2012-14): A retrospective cohort study, Lancet Infect. Dis. 15 (2015) 671-682.

[31] C.C. Holm-Hansen, S.E. Midgley, T. Kølsen Fischer, Global emergence of enterovirus D68: A systematic review, Lancet Infect. Dis. 16 (2016) e64-e75 https://doi.org/10. 1016/S1473-3099(15)00543-5.

[32] C.M. Poser, Disseminated vasculomyelinopathy. A review of the clinical and pathologic reactions of the nervous system in hyperergic diseases, Acta Neurol. Scand. 37 (1969) S1-S44.

[33] C.M. Poser, G. Román, E.S. Emery $3^{\text {rd }}$, Recurrent disseminated vasculomyelinopathy, Arch. Neurol. 35 (1978) 166-170.

[34] Y. Rodríguez, M. Rojas, Y. Pacheco, Y. Acosta-Ampudia, C. Ramírez-Santana, D.M. Monsalve, M.E. Gershwin, J.M. Anaya JM, Guillain-Barré syndrome, transverse myelitis and infectious diseases, Cell. Mol. Immunol. (2018) Jan 29.doi: https://doi. org/10.1038/cmi.2017.142

[35] C. Vellozzi, S. Iqbal, K. Broder, Guillain-Barre syndrome, influenza, and influenza vaccination: The epidemiologic evidence, Clin. Infect. Dis. 58 (2014) 1149-1155, https://doi.org/10.1093/cid/ciu005.

[36] G. Román, C.A. Phillips, C.M. Poser, Parainfluenza virus type 3: Isolation from CSF of a patient with Guillain-Barré syndrome, JAMA 240 (1978) 1613-1615.

[37] F. Araújo, R. Nogueira, M. de S. Araújo, A. Perdigão, L. Cavalcanti, R. Brilhante, M. Rocha, D.F. Vilar, S.S. Holanda, D. de M. Braga, J. Sidrim, Dengue in patients with central nervous system manifestations, Brazil, Emerg. Infect. Dis. 18 (2012) 677-679.

[38] P.N. Weeratunga, M.C. Caldera, I.K. Gooneratne, R. Gamage, P. Perera, P, Neurological manifestations of dengue: A cross sectional study, Travel Med. Infect, Dis. 12 (2014) 189-193.

[39] D.C.G. Amaral, M.A. Rachid, M.C. Vilela, R.D. Campos, G.P. Ferreira, D.H. Rodrigues, N. Lacerda-Queiroz, A.S. Miranda, V.V. Costa, M.A. Campos, E.G. Kroon, M.M. Teixeira, A.L. Teixeira, Intracerebral infection with dengue-3 virus induces meningoencephalitis and behavioral changes that precede lethality in mice, J. Neuroinflammation 8 (2011) 23, https://doi.org/10.1186/1742-20948-23.

[40] M. Puccioni-Sohler, N. Roveroni, C. Rosadas, F. Ferry, J.M. Peralta, A. Tanuri, Dengue infection in the nervous system: Lessons learned for Zika and Chikungunya, Arq. Neuropsiquiatr. 75 (2017) 123-126, https://doi.org/10.1590/0004$282 X 20160189$.

[41] M. Gupta, R. Nayak, G.A. Khwaja, D. Chowdhury, Acute disseminated encephalomyelitis associated with dengue infection: A case report with literature review, J. Neurol. Sci. 335 (2013) 216-218.

[42] L.R. Tomar, V. Mannar, S. Pruthi, A. Aggarwal, An unusual presentation of dengue fever: Association with longitudinal extensive transverse myelitis, Perm. J. 19 (2015) e133-e135.

[43] P. Gérardin, V.M. Cao-Lormeau, P. Tournebise, T. Cerny, Letter RE: Acute Zika infection with concurrent onset of Guillain-Barré syndrome, Neurology 88 (2017) 1874.

[44] W. Dejnirattisai, P. Supasa, W. Wongwiwat, W.A. Rouvinski, G. Barba-Spaeth, T. Duangchinda, A. Sakuntabhai, V.M. Cao-Lormeau, P. Malasit, F.A. Rey, J. Mongkolsapaya, G.R. Screaton, Dengue virus sero-cross-reactivity drives antibody dependent enhancement of infection with Zika virus, Nat. Immunol. 17 (2016) 1102-1108, https://doi.org/10.1038/ni.3515

[45] P.L. Timmings, R. Siu, W. Bukhari, A. Todd, W. Gunn, Author Response: Acute Zika infection with concurrent onset of Guillain-Barré syndrome, Neurology 88 (2017) 1874-1875.

[46] R. Siu, W. Bukhari, A. Todd W. Gunn, Q.S. Huang, P. Timmings, Acute Zika 
infection with concurrent onset of Guillain-Barré syndrome, Neurology 87 (2016) $1623-1624$.

[47] S. Mécharles, C. Herrmann, P. Poullain, T.H. Tran, N. Deschamps, G. Mathon, A. Landais, S. Breurec, A. Lannuzeil, Acute myelitis due to Zika virus infection, Lancet 387 (2016) 1481.

[48] E. Palacios, C. Clavijo-Prado, A. Ruiz, A. Arias Antún, E. Julián Durán, Longitudinal extensive transverse myelitis and Zika virus: A diagnostic challenge in a hospital in Colombia, Neurologia (2016), https://doi.org/10.1016/j.nrl.2016.08.006 (pii) S0213-4853(16)30200-6.

[49] I.R.F. da Silva, J.A. Frontera, A.M. Bispo de Filippis, O.J.M. do Nascimento, for the RIO-GBS-ZIKV Research Group, Neurologic complications associated with the Zika virus in Brazilian adults, JAMA Neurol. 74 (2017) 110-198, https://doi.org/10. 1001/jamaneurol.2017.1703.

[50] R.A. Romeu-Mejia, J.M. Delgado-Lebron, E. Nadal-Ortiz, Poster 363: Transverse myelitis caused by Zika virus infection in the Caribbean: A case report, PM\&R J. 9 ( (2017) S247, https://doi.org/10.1016/j.pmrj.2017.08.302.

[51] B.V.P. Casagrande, D.O. de Sousa, A.K.L.P. Machado, C.R. Mainardi, C.B. Kahwage, Transverse myelitis associated with Zika virus infection: A case report, Int. Arch. Med. 11 (2018) 1-5, https://doi.org/10.3823/2543.

[52] R.M. Galliez, M. Spitz, P.P. Rafful, M. Cagy, C. Escosteguy, C.S.B. Germano, E. Sasse, A.L. Gonçalves, P.P. Silveira, P. Pezzuto, A.M. De, M. Ornelas, A. Tanuri, R.S. Aguiar, F.T. Moll, Zika virus causing encephalomyelitis associated with immunoactivation, Open Forum Inf. Dis. 3 (2016) 1-4, https://doi.org/10.1093/ofid/ ofw203.

[53] B. Niemeyer, R. Borges, E. Marchiori, Acute disseminated encephalomyelitis following Zika virus infection, Eur. Neurol. 77 (2017) 45-46, https://doi.org/10. 1159/000453396.

[54] W. Roth, C. Tyshkov, K. Thakur, W. Vargas, Encephalomyelitis following definitive Zika virus infection, Neurol. Neuroimmunol. Neuroinflamm. 4 (2017) e349, https://doi.org/10.1212/NXI.0000000000000349.

[55] F. Pradhan, J.D. Burns, A. Agameya, A. Patel, M. Alfaqih, J.E. Small, W. Ooi, Case Report: Zika virus meningoencephalitis and myelitis and associated magnetic resonance imaging findings, Am. J. Trop. Med. Hyg. 97 (2017) 340-343, https://doi. org/10.4269/ajtmh.16-0921.

[56] L.M. Araujo, M.L.B. Ferreira, O.J.M. Nascimento, Guillain-Barré syndrome associated with the Zika virus outbreak in Brazil, Arq. Neuropsiquiatr. 74 (2016) 253-255, https://doi.org/10.1590/0004-282X20160035 (Cases reported in: Ministério da Saúde (BR), Secretaria de Vigilância em Saúde. [Protocol for surveillance and response to the occurrence of microcephaly related to Zika virus infection]. Brasília, DF: Ministério da Saúde; 2015 [cited 2015 Dec 22]. Available from), http://portalsaude.saude.gov.br/images/pdf/2015/dezembro/09/ Microcefalia-Protocolo-de-vigilância-e-resposta—vers-o-1—_09dez2015-8h.pdf , Accessed date: 10 January 2018.

[57] J.P. Stübgen, Immune-mediated myelitis following hepatitis B vaccination, Autoimmun. Rev. 12 (2012) 144-149, https://doi.org/10.1016/j.autrev.2012.03. 008.

[58] A.S. Fauci, D.M. Morens, Zika virus in the Americas - Yet another arbovirus threat, N. Engl. J. Med. 374 (2016) 601-604.

[59] J.J. Miner, M.S. Diamond, Dengue antibodies, then Zika: A fatal sequence in mice, Immunity 46 (2017) 771-773.

[60] K.L. Mansfield, D.L. Horton, N. Johnson, L. Li, A.D. Barrett, D.J. Smith, S.E. Galbraith, T. Solomon, A.R. Fooks, Flavivirus-induced antibody cross-reactivity, J. Gen. Virol. 92 (2011) 2821-2829, https://doi.org/10.1099/vir.0. 031641-0.

[61] A. Vatti, D.M. Monsalve, Y. Pacheco, C. Chang, J.M. Anaya, M.E. Gershwin, Original antigenic sin: A comprehensive review, J. Autoimmun. 83 (2017) 12-21.

[62] M.T. Medina, J.D. England, I. Lorenzana, M. Medina-Montoya, M. De Bastos, S. Fontiveros, M. Sierra, F. Contreras, Zika virus associated sensory polyneuropathy, J. Neurol. Sci. 369 (2016) 271-272.

[63] A.A. Leis, D.S. Stokic, Neuromuscular manifestations of West Nile virus infection, Front. Neurol. 3 (2012) 37, , https://doi.org/10.3389/fneur.2012.00037.

[64] N.L. Bayless, R.S. Greenberg, T. Swigut, J. Wysocka, C.A. Blish, CA, Zika virus infection induces cranial neural crest cells to produce cytokines at levels detrimental for neurogenesis, Cell Host Microbe 20 (2016) 423-428, https://doi.org/10.1016/j. chom.2016.09.006.

[65] S.L. Cumberworth, J.A. Barrie, M.E. Cunningham, D.P.G. de Figueiredo, V. Schultz, A.J. Wilder-Smith, B. Brennan, L.J. Pena, R. Freitas De Oliveira França, C. Linington, C.S.C. Barnett, H.J. Willison, A. Kohl, J.M. Edgar, Zika virus tropism and interactions in myelinating neural cell cultures: CNS cells and myelin are preferentially affected, Acta Neuropathol. Commun. 5 (2017) 50, https://doi.org/ 10.1186/s40478-017-0450-8.

[66] G. Lucchese, D. Kanduc, Zika virus and autoimmunity: From microcephaly to Guillain-Barré syndrome, and beyond, Autoimmun. Rev. 15 (2016) 801-808.

[67] F.R. Cugola, I.R. Fernandes, F.B. Russo, B.C. Freitas, J.L. Dias, K.P. Guimarães, C. Benazzato, N. Almeida, G.C. Pignatari, S. Romero, C.M. Polonio, I. Cunha, C.L. Freitas, W.N. Brandão, C. Rossato, D.G. Andrade, D. de P. Faria, A.T. Garcez, C.A. Buchpigel, C.T. Braconi, E. Mendes, A.A. Sall, P.M. Zanotto, J.P. Peron, A.R. Muotri, P.C. Beltrão-Braga, The Brazilian Zika virus strain causes birth defects in experimental models, Nature 534 (2016) 267-271, https://doi.org/10.1038/ nature18296.

[68] H.M. Lazear, J. Govero, A.M. Smith, D.J. Platt, E. Fernandez, J.J. Miner, M.S. Diamond, A mouse model of Zika virus pathogenesis, Cell Host Microbe 19 (2016) 720-730, https://doi.org/10.1016/j.chom.2016.03.010.

[69] G. Morris, T. Barichello, B. Stubbs, C.A. Köhler, A.F. Carvalho, M. Maes, Zika virus as an emerging neuropathogen: Mechanisms of neurovirulence and neuro-immune interactions, Mol. Neurobiol. (2017) 1-25, https://doi.org/10.1007/s12035-0170635-y.

[70] N.C.C. Fernandes, J.S. Nogueira, R.A. Réssio, C.S. Cirqueira, L.M. Kimura, K.R. Fernandes, M.S. Cunha, R.P. Souza, J.M. Guerra, Experimental Zika virus infection induces spinal cord injury and encephalitis in newborn Swiss mice, Exp. Toxicol. Pathol. 69 (2017) 63-71, https://doi.org/10.1016/j.etp.2016.11.004.

[71] L. Chimelli, A.S.O. Melo, E. Avvad-Portari, C.A. Wiley, A.H.S. Camacho, V.S. Lopes, H.N. Machado, C.V. Andrade, D.C.A. Dock, M.E. Moreira, F. Tovar-Moll, P.S. Oliveira-Szejnfeld, A.C.G. Carvalho, O.N. Ugarte, A.G.M. Batista, M.M.R. Amorim, F.O. Melo, T.A. Ferreira, J.R.L. Marinho, G.S. Azevedo, J.I.B.F. Leal, R.F.M. da Costa, S. Rehen, M.B. Arruda, R.M. Brindeiro, R. Delvechio, R.S. Aguiar, A. Tanuri, The spectrum of neuropathological changes associated with congenital Zika virus infection, Acta Neuropathol. 133 (2017) 983-999, https:// doi.org/10.1007/s00401-017-1699-5.

[72] S.V. Bardina, P. Bunduc, S. Tripathi, J. Duehr, J.J. Frere, J.A. Brown, R. Nachbagauer, G.A. Foster, D. Krysztof, D. Tortorella, S.L. Stramer, A. GarcíaSastre, F. Krammer, J.K. Lim, Enhancement of Zika virus pathogenesis by preexisting antiflavivirus immunity, Science 356 (2017) 175-180, https://doi.org/10. 1126/science.aal4365.

[73] H.D. Marston, N. Lurie, L.L. Borio, A.S. Fauci, Considerations for developing a Zika virus vaccine, N. Engl. J. Med. 375 (2016) 1209-1212, https://doi.org/10.1056/ NEJMp1607762.

[74] G.A. Poland, R.B. Kennedy, I.G. Ovsyannikova, R. Palacios, P.L. Ho, J. Kalil, Development of vaccines against Zika virus, Lancet Infect. Dis. (2018), https://doi. org/10.1016/S1473-3099(18)30063-X (pii: S1473-3099(18)30063-X). 